\title{
PROBABILITY FLUCTUATIONS IN THE RATE OF EMISSION OF $\alpha$ PARTICLES
}

\author{
By L. F. Curtiss
}

\section{ABSTRACT}

The deviation from a simple probability distribution of the rate of emission of $\alpha$ particles from polonium has been investigated as a preliminary step to the investigation of the relation of the phenomenon of aggregate recoil to this anomalous behavior of polonium sources. This work shows that a freshly prepared source exhibits a subnormal dispersion which after about 35 days has become normal as tested by the divergence coefficient $Q^{2}$. This is in agreement of observations by Kutzner (Zs. fur Phys., 21, p. 281; 1924).

\section{CONTENTS}

I. Introduction

II. Experimental method and results

III. Discussion

598

\section{INTRODUCTION}

The fluctuation in the rate of emission of $\alpha$ particles from radioactive sources has frequently been investigated since it was first studied theoretically by $\mathrm{v}$. Schweidler ${ }^{1}$ early in the development of the subject of radioactivity. The general results of these investigations have been to confirm that, within limits of error of observation, this fluctuation in the rate of emission of $\alpha$ particles is exactly that to be expected on the basis of simple probability. The distribution in time is a purely random distribution. More recently, however, Kutzner ${ }^{2}$ has performed experiments bearing on this question. $\mathrm{He}$ used improved electrical methods of counting and registration. These eliminated uncertainties present in earlier studies as a result of visual counting and recording by hand as is necessary in the scintillation method. To test his results he employed the divergence coefficient $Q^{2}$ of Lexis which in this case is defined by

$$
Q^{2}=\frac{\sum_{0}^{x} l_{x} x^{2}}{L}-m
$$

where $l_{x}$ is the number of equal intervals with $x \alpha$ particles, $m$ is the average number per interval, and $L$ is the total number of $\alpha$ particles observed. For a purely chance distribution $Q^{2}=1$. If it is greater than unity a supernormal dispersion exists and if it is less, the dispersion is subnormal. Kutzner found, in general, a subnormal dispersion and assigned this deviation from a simple probability distribution to an interaction between disintegrating atoms. He ob-

1 E. V. Schweidler, Congrès Internationale de Radiologie, Liege; 1905.

2 W. Kutzner, Zs. f. Phys., 21, 281; 1924. 
served that this deviation was greatest in freshly prepared sources. As the source became older the divergence coefficient approached unity.

The present work was undertaken to study this deviation from a probability distribution. This paper gives a summary of a series of observations with a polonium source which were made as a preliminary step to the main investigation. Somewhat different methods of recording were used from those employed by Kutzner and each set of observations extended over six or seven hours instead of about one hour as in his case.

\section{EXPERIMENTAL METHOD AND RESULTS}

A diagram of the arrangement of the counting chamber and the polonium source is shown in Figure 1. The counting chamber $C$, supported on a bakelite base, $A$, had an opening $3 \mathrm{~mm}$ in diameter in the front end covered by a mica window, $M$, of about $1 \mathrm{~cm}$ stopping power. The source, $S$, polonium deposited on the polished end of a bismuth rod, was supported inside the end of the glass tube, $R$, directly opposite the window, $M$, and about $2 \mathrm{~cm}$ from it. To limit

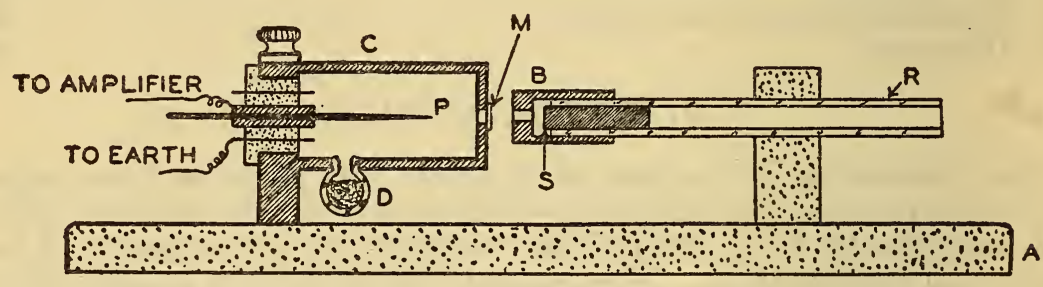

FIGURE 1.-Arrangement of point counter and polonium source

the size of the $\alpha$ particle beam a brass bushing, $B$, was slipped over the end of the glass tube, $R$, as shown. The face of this bushing was $5 \mathrm{~mm}$ thick and had a hole $2 \mathrm{~mm}$ in diameter in the center. This hole also was directly opposite the mica window, $M$.

An important feature of the counting chamber is the drying bulb shown at $D$ in Figure 1 . The chamber was hermetically sealed at all joints so that no gases or vapors could enter. Thus, the drying bulb made it certain that at all times the chamber was filled with dry air. It was found with this arrangement that a point once prepared would work almost indefinitely at the same voltage applied to the counting chamber. All observations were taken with a single point prepared some weeks before the experiments were started. It appears that the difficulties in maintaining points in a satisfactory condition experienced by those who have worked with this type of counter arise chiefly from the effects of gases and vapors from the room which have a deleterious effect on the action of the point.

The point of the counting chamber was connected to a vacuum tube amplifier, described elsewhere. ${ }^{3}$ By this arrangement the pen of a specially constructed chronograph could be actuated each time the counter responded to the entrance of an $\alpha$ particle. The chronograph used a continuously moving paper ribbon and was driven by an electric motor. A second pen worked close beside the first, marking every six

8 L. F. Curtiss, Phys. Rev., 31, p. 1060; 1928. 
seconds and driven from a standard clock circuit. This made the determination of the number of $\alpha$ particles per interval relatively easy.

The source was adjusted to give a count of about 60 particles per minute. At this speed of counting the effect of close doubles was almost eliminated for the resolving power of apparatus used. Each set of observations contained between 20,000 and $30,000 \alpha$ particles and required about six or seven hours. Within this time the decay of the polonium source was so slight that it could be neglected.

Observations were made on 18 days in an interval of time extending over 42 days. An example of the results obtained and the method of computation of $Q^{2}$ is given in Table 1 .

TABLE 1

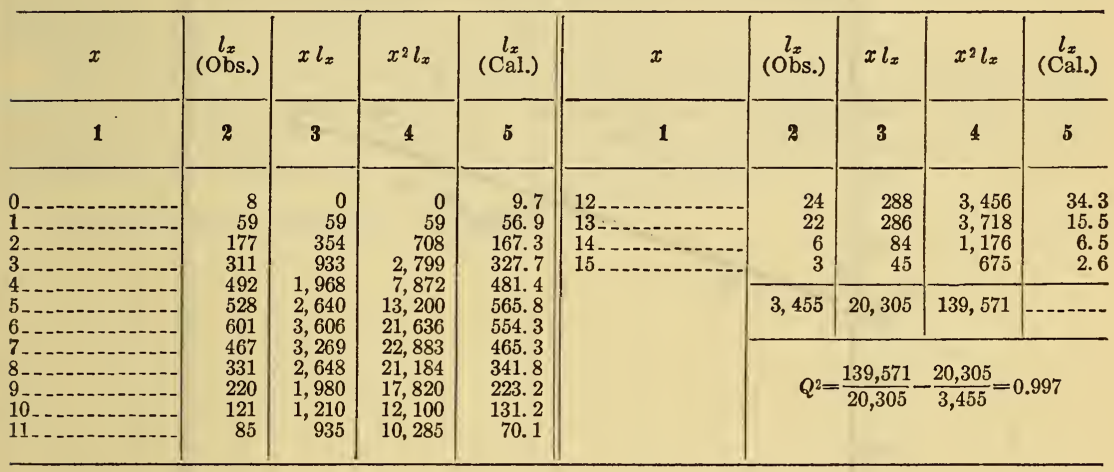

In column 1 is given $x$, the number of $\alpha$ particles per uniform interval of time. In the example here given $x$ ranged from 0 to 15 . Column 2 gives $l_{x}$, the number of intervals having $x \alpha$ particles. Column 3 gives $x l_{x}$, the total number of $\alpha$ particles in intervals having $x$ $\alpha$ particles each. Thus $\Sigma x l_{x}=L$, the total number of $\alpha$ particles counted. Column 4 gives $x^{2} l_{x}$ used in computing $Q^{2}$. In column 5 is given the values of $l_{x}$ as calculated by Bateman's ${ }^{4}$ formula, $L_{x}=s \frac{m^{x} e^{-m}}{x !}$ where $s=\Sigma l_{x}$ or the total number of intervals.

In Table 2 , the results of 18 sets of observations are given. The first column gives the date on which the observations were made. The second column gives the total elapsed time in days since the preparation of the source. Column 3 gives the value of $m$ for each set of observations and the last column contains the corresponding $Q^{2}$. These data are shown graphically in Figure 2, where the values of $Q^{2}$ are plotted against time starting from the preparation of the source. The solid line is drawn in roughly to show the general trend of the value of $Q^{2}$, while the dotted line represents the theoretical value of $Q^{2}=1$.

4. Bateman, Phil. Mag., 20, p. 698; 1910. 
TABLE 2

\begin{tabular}{|c|c|c|c|c|c|c|c|}
\hline Date & Time & $\mathrm{m}$ & $Q^{2}$ & Date & Time & $\mathrm{m}$ & $Q^{2}$ \\
\hline 1 & 2 & 3 & 4 & 1 & 2 & 3 & 4 \\
\hline $\begin{array}{l}\text { May } 15 \\
\text { May } 23 \\
\text { May } 24 \\
\text { May } 25 \\
\text { May } 31 \\
\text { June } 4 \\
\text { June } 7 \\
\text { June } 10 \\
\text { June } 11\end{array}$ & $\begin{array}{r}1 \\
9 \\
10 \\
11 \\
17 \\
21 \\
24 \\
27 \\
28\end{array}$ & $\begin{array}{l}8.21 \\
6.00 \\
6.39 \\
6.19 \\
5.98 \\
5.73 \\
5.71 \\
5.51 \\
5.54\end{array}$ & $\begin{array}{l}0.875 \\
.870 \\
.863 \\
.892 \\
.983 \\
.932 \\
.929 \\
.925 \\
.915\end{array}$ & $\begin{array}{l}\text { June } 12 \\
\text { June } 13 . \\
\text { June } 14 \\
\text { June } 17 \\
\text { June } 18 \\
\text { June } 19 \\
\text { June } 24 \\
\text { June } 25 \\
\text { June 26... }\end{array}$ & $\begin{array}{l}29 \\
30 \\
31 \\
34 \\
35 \\
36 \\
41 \\
42 \\
43\end{array}$ & $\begin{array}{l}6.01 \\
5.65 \\
5.40 \\
5.62 \\
6.09 \\
6.38 \\
5.49 \\
5.88 \\
5.80\end{array}$ & $\begin{array}{l}0.924 \\
.935 \\
1.024 \\
.943 \\
1.005 \\
.990 \\
1.002 \\
.997 \\
.962\end{array}$ \\
\hline
\end{tabular}

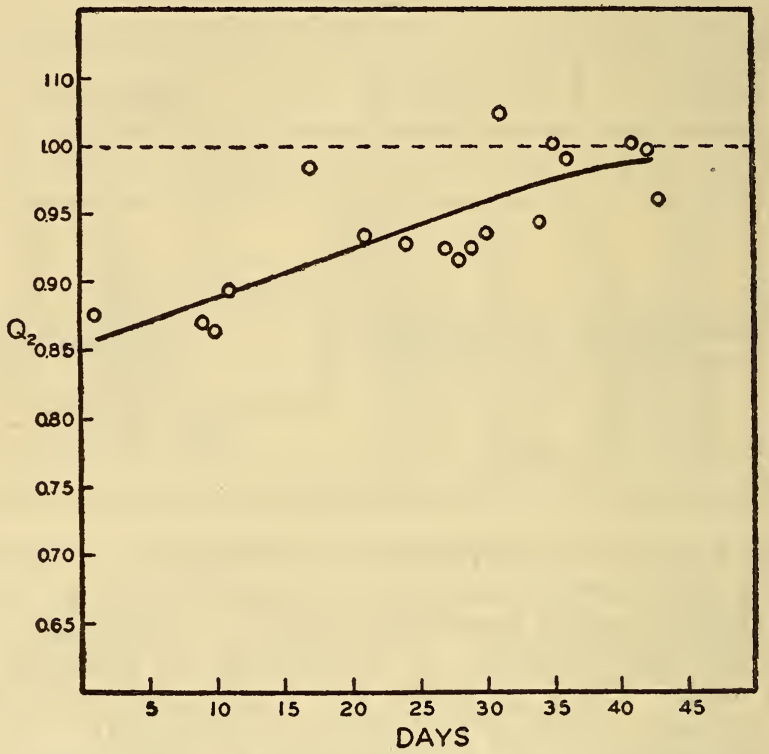

Figure 2.-Graphical representation of change of $Q^{2}$ with age of polonium source

\section{DISCUSSION}

These observations are in full agreement with the results obtained by Kutzner under somewhat different conditions. The initial value of $Q^{2}$ for a freshly prepared source is decidedly below unity and gradually approaches this theoretical value, which in this case was reached roughly after about 35 days. Kutzner reports even lower values of $Q^{2}$ which probably arises from the fact that he used stronger preparations of polonium.

Lawson ${ }^{5}$ has called attention to the phenomenon of aggregate recoil and expressed the opinion that the anomalous behavior of the $\alpha$ radiation can be explained as follows: The active material on a metal surface is arranged in separate groups of molecular aggregates. When an $\alpha$ particle is emitted from an atom of one of these aggregates in toward the metal the recoil may detach many other atoms

R. W. Lawson, Nature, 114, p. 121; 1924. 
besides the disintegrating atom. Since some of these will be polonium atoms which have not yet disintegrated, this will increase the rate of decay of the preparation. It will also disturb the probability distribution in just the way that the experiments have shown, and would account for the gradual improvement in the value of $Q^{2}$, for there would be less likelihood of aggregate recoil in an older preparation. All easily detached aggregates would then have been torn off. As Lawson points out, this is a much simpler explanation and does not involve the radical assumption of atomic disintegration of a heavy atom by an $\alpha$ particle of such low energy as that possessed by polonium $\alpha$ particles.

Enough information is not yet available to prove that this distortion of the probability curve is the result of aggregate recoil. Further experiments under conditions where this phase of the behavior of a preparation can be carefully controlled seem desirable to make certain that this simple explanation is the correct one.

The writer is pleased to acknowledge the help of L. L. Stockmann and H. L. Martin in making the records of $\alpha$ particles. He is also indebted to Miss C. L. Torrey for considerable help in counting the records and making the necessary computations.

WASHINGTON, October 15, 1929. 